\title{
Research of stress distribution in the cross-section of a bimetallic perforated plate perpendicularly loaded with concentrated force
}

\author{
Mateusz Marcin Konieczny, Henryk Achtelik, Grzegorz Gasiak \\ Opole University of Technology, Poland \\ mateuszmarcinkonieczny@wp.pl,kmpkm@po.edu.pl,s.gasiak@po.edu.pl
}

\begin{abstract}
The paper presents the stress distribution along the plate thickness in a bimetallic steel - titanium circular perforated plate produced in the technological process of explosion welding. The steel layer is the layer that transfers the load in the plate, while the titanium layer is used to improve the properties of the plate, e.g. corrosion resistance, thermal transmittance, etc. in the plate. Two cases of fastening were considered, i.e. a freely supported and fixed plate. Such plates are used in various engineering structures, e.g. simply supported plates can be used in loose material screens, while plates are fixed in heat exchangers. The load was assumed as a concentrated force applied perpendicularly to the plate surface. The results obtained numerically using the finite element method were compared with the results calculated according to the analytical equations. It has been shown that the difference in the results of equivalent von Mises stress calculations does not exceed 13\%. The research results presented in the paper can be used by engineers to design bimetallic perforated plates perpendicularly loaded to their surface.
\end{abstract}

KEYwORDS. Bimetallic perforated plate; Concentrated force; Stress analysis; Analytical calculations; Numerical calculations

\section{OPEN ACCESS}

Citation: Konieczny, M. M., Achtelik, H., Gasiak, G., Research of stress distribution in the cross-section of a bimetallic perforated plate perpendicularly loaded with concentrated force, Frattura ed Integrità Strutturale, 55 (2021) 241-257.

Received: 13.11 .2020

Accepted: 17.12 .2020

Published: 01.01.2021

Copyright: (C) 2019 This is an open access article under the terms of the CC-BY 4.0, which permits unrestricted use, distribution, and reproduction in any medium, provided the original author and source are credited.

\section{INTRODUCTION}

I $\mathrm{n}$ engineering structures, structural elements consisting of many layers [1, 2] and of many materials [3] are often used plated elements called metallic composites [4, 5]. Metallic composites (plating) are obtained by so-called explosive welding. Explosive welding, or bonding, makes it possible to join together many groups of construction materials by means of the energy released during the detonation of the explosive [6]. The unquestionable advantage of the explosive technology is the possibility of joining together materials that currently cannot be permanently joined by conventional methods such as: soldering, gluing or welding. However, the key benefit of using metal composites is the ability to significantly reduce the cost of making a given structure by reducing the amount of expensive materials with unique properties. An example of this type of material is bimetal steel - titanium, which, when used in engineering structures, maintains the assumed strength and anti-corrosion parameters, ensuring work safety, while reducing the amount of expensive titanium used. 
The main applications of steel - titanium plated materials include high-pressure tanks and highly specialized elements of process equipment, e.g. heat exchanger tube sheets (Fig. 1). Elements made of bimetal steel - titanium are most often used due to the improvement of physical properties, thermal properties, chemical properties (e.g. corrosion resistance) as well as mechanical parameters of a given structure in which such elements are present.

In heat exchangers, an important issue is the analysis of the complex effect of the perforated plate on the connected shell of the chemical apparatus and the associated stress distribution in the shell, in the tubes and in the perforated plate itself [7, 8 , 9]. Contemporary engineering structures, compared to their predecessors, are characterized by a reduced safety factor. Therefore, the precise calculation of temporary strength, stiffness and stability, in particular of thin-walled structural elements, is of increasing importance.

Literature studies indicate the widening perspective of the use of plated materials [10,11,12,13]. The paper proposes an analytical and numerical approach to determining the value of stresses along the plate thickness in a bimetallic circular axially symmetrical perforated plate, freely supported at the edge and fixed at the edge and centrally loaded with a concentrated force $P$ perpendicular to the plate surface. The research conducted at work was carried out on the basis of the finite element method (FEM) and the analytical method according to mathematical formulas. A novelty in this work is the development and application of the analytical method to determine the stress state in the transition zone between the titanium layer and the steel layer in a bimetallic perforated plate loaded with e.g. a concentrated force.

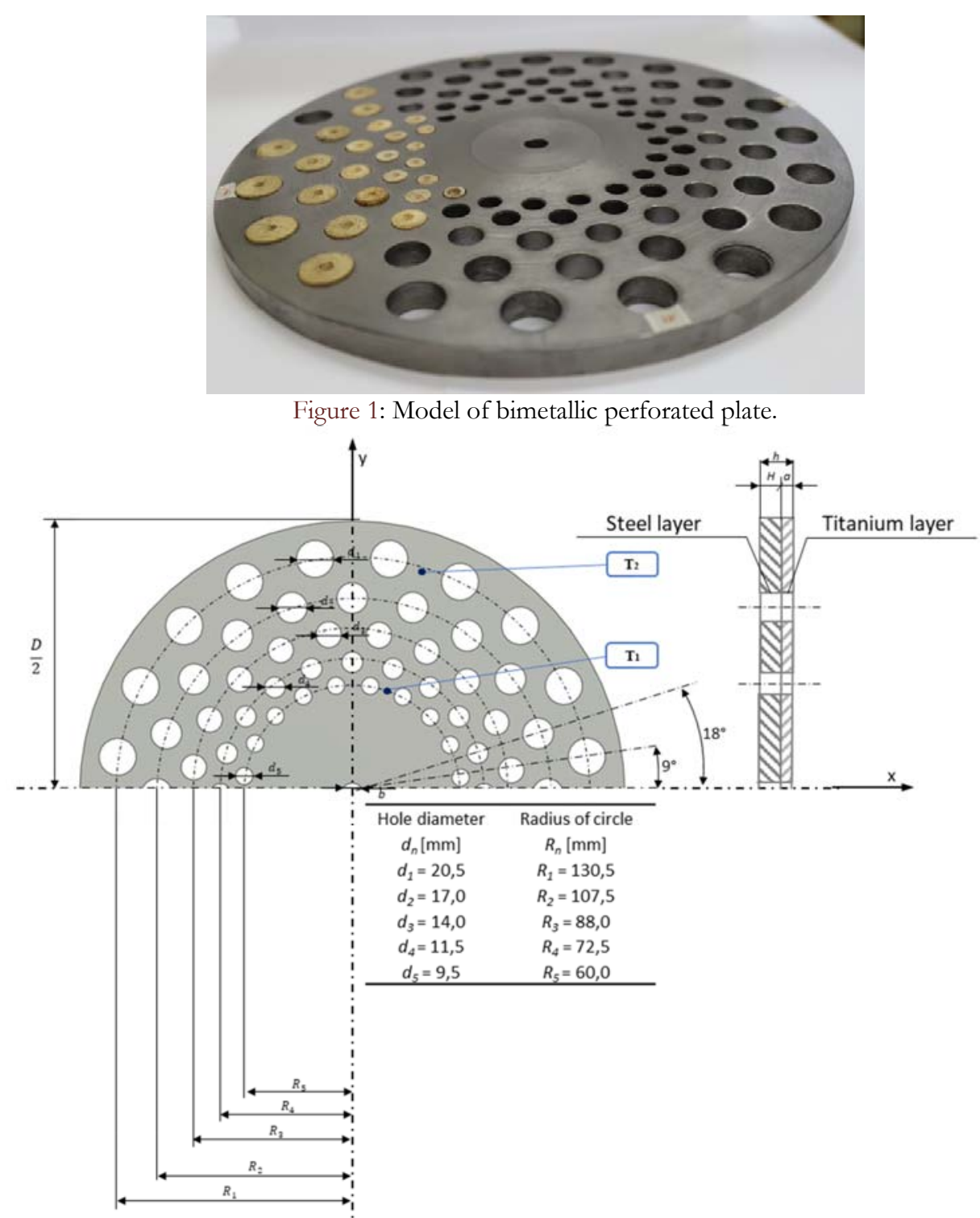

Figure 2: Model of bimetallic perforated plate consisting of steel thickness perforated plate $H$ and titanium perforated plate thickness $a$ containing holes with diameters $d_{1}, \ldots, d_{5}$ and sections $T_{1}$ and $T_{2}$. 


\section{MATERIAL AND GEOMETRY}

$\mathrm{T}$ he calculation was based on a bimetallic circular axisymmetric perforated plate with dimensions: diameter $D=300$ $\mathrm{mm}$ and comprising two layers, i.e. the base layer $\mathrm{B}$ in the form of structural steel with a thickness of $H=10 \mathrm{~mm}$ and the applied layer (plating) in the form of titanium with the thickness of $a=2.5 \mathrm{~mm}$. 100 holes with different radii located on the plate. These holes were arranged in five circles with 20 holes in each circle. On the first outer circle, the plate had holes $d_{1}=20.5 \mathrm{~mm}$ in diameter and on the fifth, inner circle holes $d_{5}=9.5 \mathrm{~mm}$ in diameter (Fig. 2). Steel plate grade S355J2 was adopted as the base material, and titanium sheet was adapter as the applied material with the following mechanical and material parameters (Tab. 1) [14]. The materials used in the work, titanium and steel included in the bimetallic perforated plate, were modeled as elastic materials.

\begin{tabular}{|c|c|c|c|c|c|c|}
\hline \multicolumn{7}{|c|}{$\mathrm{S} 355 \mathrm{~J} 2$ steel and titanium } \\
\hline \multicolumn{7}{|c|}{ Applied layer A - titanium } \\
\hline $\mathrm{R}_{e}[\mathrm{MPa}]$ & $\mathrm{R}_{\mu \prime}[\mathrm{MPa}]$ & $E[\mathrm{GPa}]$ & $\boldsymbol{v}[-]$ & $G$ [GPa] & $A 5[\%]$ & \\
\hline $189-215$ & 308-324 & 100 & 0.37 & 36.5 & $43-56$ & \\
\hline $\mathrm{C}$ & $\mathrm{Fe}$ & $\mathrm{H}$ & $\mathrm{N}$ & $\mathrm{O}$ & $\mathrm{Ti}$ & \\
\hline 0.10 & 0.20 & 0.015 & 0.03 & 0.18 & 99.5 & \\
\hline \multicolumn{7}{|c|}{ Base layer B - S355J2 steel } \\
\hline $\mathrm{R}_{e}[\mathrm{MPa}]$ & $\mathrm{R}_{m}[\mathrm{MPa}]$ & $E$ [GPa] & $\boldsymbol{v}[-]$ & $G$ [GPa $]$ & $A 5[\%]$ & \\
\hline 382-395 & $598-605$ & 220 & 0,30 & 84,6 & $24-34$ & \\
\hline C & $\mathrm{Si}$ & $\mathrm{Mn}$ & $\mathrm{P}$ & S & $\mathrm{Cu}$ & $\mathrm{Fe}$ \\
\hline 0.22 & 0.55 & 1.60 & 0.025 & 0.025 & 0.45 & all \\
\hline
\end{tabular}

Table 1: Strength properties and chemical composition of S355J2 steel and titanium, where: $R_{e}-$ yield strength $[\mathrm{MPa}], R_{m}-$ tensile strength [MPa], E- Young's modulus [GPa], $\boldsymbol{v}$ - Poisson's ratio [-], A5 - tensile elongation [\%].

\section{ANALYTICAL METHOD}

$\mathrm{U}$ nlike the classical form of plate bending theory [15], in which the analysis is concerned with the state of equilibrium of internal forces acting on the separated full plate element, in this case the state of equilibrium of the plate element containing the halves of the holes is considered (Fig. 2) [16] and described in the cylindrical coordinate axis system $r, \theta, \%$ The following variables can be found in Fig. 3:

$\$ m_{\theta_{1}}, m_{\theta_{2}}-$ circumferential torque intensity in the steel and titanium parts, respectively;

$\$ m_{r_{1}}, m_{r_{2}}-$ radial torque intensity in the steel and titanium parts, respectively;

$+\sigma_{\theta_{1}}, \sigma_{\theta_{2}}$ - circumferential stress in the steel and titanium parts;

* $\sigma_{r_{1}}, \sigma_{r_{2}}$-radial stress in the steel and titanium parts;

\# $E_{1}, E_{2}, v_{1}, v_{2}$ - Young's modules and Poisson's ratios for steel and titanium parts respectively;

$\# b_{1}, h_{2}-$ values determining the position of the inert layer in the cross-section of the plated plate;

$\# b$-total thickness of the plate;

$t(r)$ - intensity of transverse force acting in cross-sections of the plated plate.

The conditions of equilibrium of internal forces presented in Fig. 3 result in the following form of a differential equation [15] describing the state of plate effort: 


$$
\frac{d m_{r}}{d r}+\frac{m_{r}-m_{\theta}}{r}=-t(r)
$$

The intensity of moments $m_{r 1}, m_{r 2}, m_{\theta 1}, m_{\theta 2}$ in a bimetallic perforated plate are expressed by the respective relations [16]:

$$
\begin{aligned}
& m_{r}=m_{r_{1}}+m_{r_{2}}=C_{r}\left(B^{*} \frac{d \varphi}{d r}+B^{* *} \frac{\varphi}{r}\right) \\
& m_{\theta}=m_{\theta_{1}}+m_{\theta_{2}}=C_{\theta}\left(B^{* *} \frac{d \varphi}{d r}+B^{*} \frac{\varphi}{r}\right)
\end{aligned}
$$

where:

$\varphi-$ is the angle of inclination tangential to the curved central surface of the plate.

$B^{*}=B_{1}+B_{2}$

$B^{* *}=v_{1} B_{1}+v_{2} B_{2}$

$B_{1}=\frac{E_{1}}{3\left(1-v_{1}^{2}\right)}\left(b_{1}^{3}+h_{2}^{3}\right) ; B_{2}=\frac{E_{2}}{3\left(1-v_{2}^{2}\right)}\left[\left(h_{2}+a\right)^{3}-b_{2}^{3}\right] ;-$ bending strength of the steel and titanium layer, respectively.

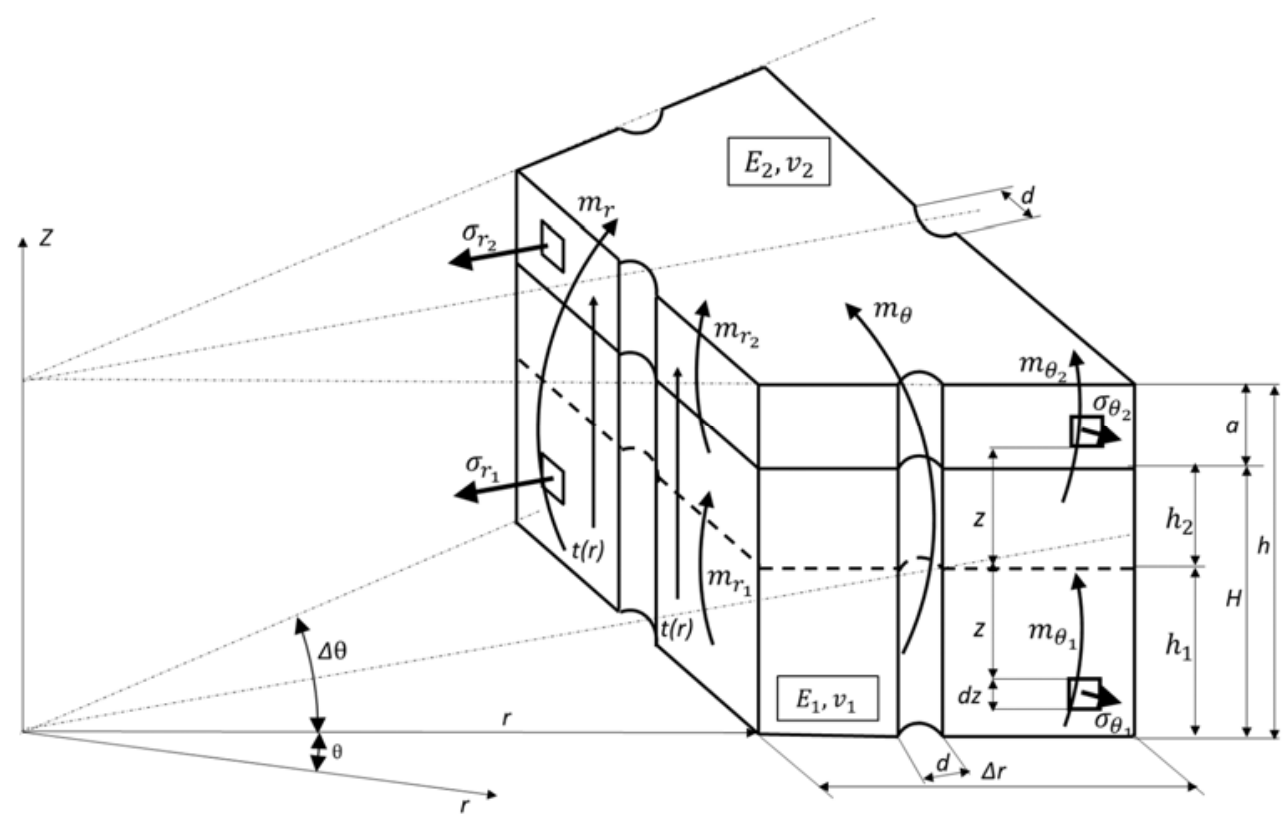

Figure 3: Wedge element cut from a bimetallic perforated plate in a state of static equilibrium.

The $C_{r}, C_{\theta}$ coefficients determine the degree of weakening of the cross-section due to the existence of discontinuities in the form of perforations (Fig. 2) in the radial and circumferential direction. They were adopted in the respective form [16]:

$$
C_{r}=\frac{r \Delta \theta-d}{r \Delta \theta} ; C_{\theta}=\frac{\Delta r-d}{\Delta r}
$$

where: $\Delta r, \Delta \theta$ - finite increments of radial coordinate $r$ and circumferential one $\theta ; d$ - diameter of the perforation. After introducing compounds (2), (3) into Eqn. (1), the following form was obtained: the equilibrium of internal forces acting on the element of the bimetallic circular perforated plate (Fig. 3): 


$$
\frac{d^{2} \varphi}{d r^{2}}+\left[1+\left(1-\frac{C_{\theta}}{C_{r}}\right) \frac{B^{* *}}{B^{*}}\right] \frac{1}{r} \frac{d \varphi}{d r}-\frac{C_{\theta}}{C_{r}} \frac{\varphi}{r^{2}}=-\frac{t(r)}{C_{r} B^{*}}
$$

where the function of the transverse force intensity $t(r)$ for the most common methods of plate support was assumed to take the form [16]:

$$
t(r)=k_{1} r+\frac{k_{2}}{r}+k_{3} r^{2}
$$

where: $k_{1}, k_{2}, k_{3}-$ lateral force function coefficients.

The solution to Eqn. (5) is given by the function of the plate deflection angle $\varphi(r)$ :

$$
\varphi(r)=\frac{-1}{C_{r} B^{*}}\left[\frac{k_{1} r^{3}}{\left(3-\lambda_{1}\right)\left(3-\lambda_{2}\right)}+\frac{k_{2} r}{\left(1-\lambda_{1}\right)\left(1-\lambda_{2}\right)}+\frac{k_{3} r^{4}}{\left(4-\lambda_{1}\right)\left(4-\lambda_{2}\right)}\right]+D_{1} r^{\lambda_{1}}+D_{2} r^{\lambda_{2}}
$$

in which $\lambda_{1}$ and $\lambda_{2}$ are roots of the characteristic equation:

$$
\lambda^{2}+\frac{B^{* *}}{B^{*}}\left(1-\frac{C_{\theta}}{C_{r}}\right) \lambda-\frac{C_{\theta}}{C_{r}}=0
$$

In function (7), which is the general integral of the differential Eqn. (5), the constant coefficients $k_{1}, k_{2}, k_{3}$ depend on the load method, while $D_{1}$ and $D_{2}$ are integration constants whose numerical values are determined on the basis of the boundary conditions given in this study. After determining the function $\varphi(r)$ from compounds (2) and (3), the intensities of radial and circumferential moments in the base material (steel) $m_{r 1}, m_{\theta 1}$ and in the plating layer (titanium) $m_{r 2}$, $m_{\theta 2}$ are determined. The deflection of the bimetallic perforated plate with the plating layer is determined by the relationship:

$$
w(r)=-\int \varphi(r) d r+D_{3}
$$

where $D_{3}$ - integration constant.

The stress in the cross-sections of the bimetalic perforated plate (Fig. 3) is derived on the basis of the compounds:

1) Radial stress $\sigma$ :

a) in the base material of the plate (steel) $\sigma_{r_{1}}$ :

$$
\sigma_{r_{1}}=\frac{3 m_{r_{1}}}{C_{r}\left(b_{1}^{3}+h_{2}^{3}\right)} z, \text { dla }-b_{1} \leq z \leq b_{2}
$$

b) in the applied layer of the plate (titanium) $\sigma_{r_{2}}$ :

$$
\sigma_{r_{2}}=\frac{3 m_{r_{2}}}{C_{r}\left[\left(h_{1}+a\right)^{3}-b_{2}^{3}\right]^{2}} \text {, dla } h_{2} \leq z \leq\left(h_{2}+a\right)
$$

2) Circumferential stress $\sigma_{\theta}$ :

a) in the base material of the plate (steel) $\sigma_{\theta_{1}}$ :

$$
\sigma_{\theta_{1}}=\frac{3 m_{\theta_{1}}}{C_{\theta}\left(h_{1}^{3}+h_{2}^{3}\right)} z, \mathrm{dla}-h_{1} \leq z \leq h_{2}
$$


b) in the applied layer of the plate (titanium) $\sigma_{\theta_{2}}$ :

$$
\sigma_{\theta_{2}}=\frac{3 m_{\theta_{2}}}{C_{\theta}\left[\left(b_{2}+a\right)^{3}-b_{2}^{3}\right]^{2}} \text {, dla } h_{2} \leq z \leq\left(b_{2}+a\right)
$$

The equivalent von Mises stress was determined from the relationship:

a) for the steel layer:

$$
\sigma_{r d_{1}}=\sqrt{\sigma_{r_{1}}^{2}+\sigma_{\theta_{1}}^{2}-\sigma_{r_{1}} \sigma_{\theta_{1}}}
$$

b) for the titanium layer:

$$
\sigma_{\text {red }_{2}}=\sqrt{\sigma_{r_{2}}^{2}+\sigma_{\theta_{2}}^{2}-\sigma_{r_{2}} \sigma_{\theta_{2}}}
$$

In the formulas for determining the intensity of bending moments in the radial direction (2) and circumferential direction (3) as well as in the formulae applied for determining the stresses in the radial direction (10) and (11) and circumferential directions (12) and (13) $h_{1}$ and $h_{2}$ determine the position of the layer inert sections of the plate (Fig. 3):

$$
\begin{aligned}
& h_{2}=\frac{E_{1} H^{2}-E_{2} a^{2}}{2\left(E_{1} H+E_{2} a\right)} \\
& h_{1}=H-b_{2}
\end{aligned}
$$

where:

$h_{1}, h_{2}$ - values determining the state of the inactive layer in the cross section of the steel plate; $E_{1}, E_{2}-$ Young's modules for the steel and titanium parts; $H, a$ - thickness of steel and titanium plate, respectively.

Inactive layer of the plate - it is a layer in which the deformations are equal to zero $[15,16]$.

Bimetallic perforated plate freely supported on the perimeter and loaded with a concentrated force P acting perpendicular to the surface In the first case, the analysis the state of stress in a bimetallic perforated plate loaded with a concentrated force applied perpendicularly to the surface with the value $P=10 \mathrm{kN}$ was presented below. The geometry of the plate is presented in Fig. 2 . The concentrated force $P$ was applied centrally to the pressure stamp with a diameter of $b_{1}=14$ mm. A free support of the plate on the outer perimeter was assumed. The method of support and loading the plate is shown in Fig. 4.

The boundary conditions are assumed to take the following form (Fig. 4):

a) for the radius $r-1 / 2 b=6 \mathrm{~mm}$ - plate deflection angle $\varphi=0$;

b) for the radius $r=1 / 2 D=150 \mathrm{~mm}$ - radial moment strength $m_{r}=0$.

In this case, the coefficients $k_{1}, k_{2}, k_{3}$ inside the function of the lateral force intensity $t(r)(6)$ are equal to, respectively:

$$
k_{1}=0 ; k_{2}=\frac{P}{2 \pi} ; k_{3}=0
$$

The roots of the Eqn. (8) $\lambda_{1}$ and $\lambda_{2}$ are:

$$
\lambda_{1}=1.127[-] ; \lambda_{2}=-1.065[-]
$$


Integration constants $D_{1}$ and $D_{2}$ in the Eqn. (7) are equal to:

$$
D_{1}=-1.21545 * 10^{-7} k_{2}[\mathrm{~mm}] ; D_{2}=-5.1032 * 10^{-5} k_{2}[\mathrm{~mm}]
$$

Cross-section weakening coefficients (4) $C_{\theta}$ and $C_{r}$ in the analyzed plate are respectively:

$$
C_{\theta}=0.590[-] ; C_{r}=0.496[-]
$$

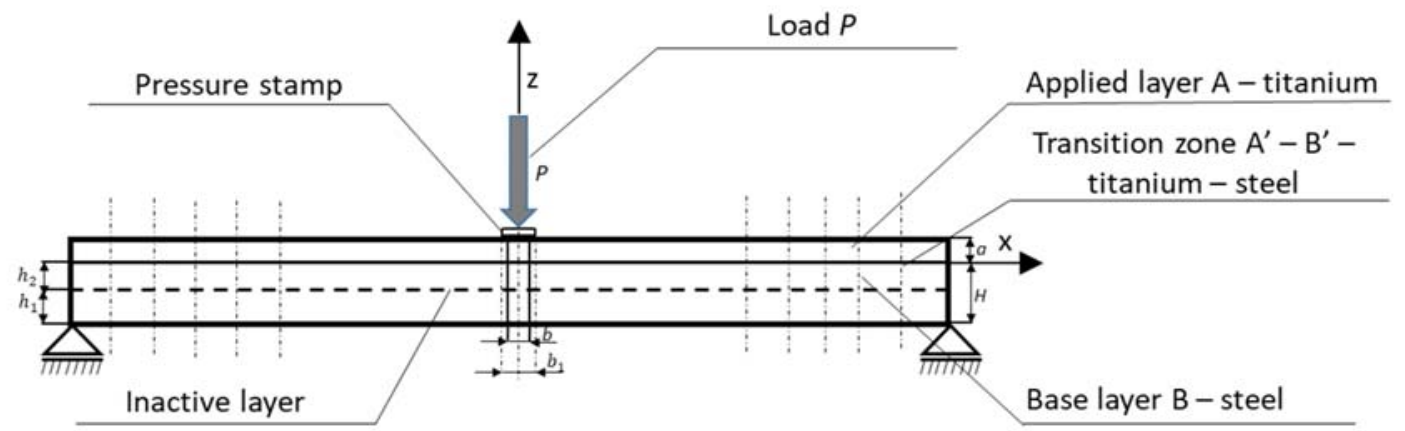

Figure 4. Bimetallic perforated plate freely supported on the perimeter and loaded with a concentrated force $P$ acting perpendicular to the surface.

For calculations it was assumed:

\& $P=10 \mathrm{kN}$ - load in the form of concentrated force distributed around the circumference of the hole with a diameter;

+ $b=12 \mathrm{~mm}$ - hole diameter;

\# $b_{1}-14 \mathrm{~mm}$ - pressure stamp diameter;

\# $D=300 \mathrm{~mm}-$ outer diameter of the plate;

\# $H=10 \mathrm{~mm}$ - base layer thickness (steel plate);

\# $a=2.5 \mathrm{~mm}$ - applied layer thickness (titanium plate);

$\$ h_{1}=5.64 \mathrm{~mm}$ (Fig. 2);

\# $h_{2}=4.36 \mathrm{~mm}$ (Fig. 2);

The mechanical properties of the steel plate and titanium plate are taken from Tab. 1.

On the basis of the Eqns. (10) - (15), values of radial stresses $\sigma_{r}^{a}$ and circumferential $\sigma_{\theta}^{a}$ and equivalent von Mises stresses $\sigma_{\text {red }}^{a}$ were determined for the adopted geometry of the bimetallic perforated plate given in Fig. 4. For example, in Fig. 5 the values of the circumferential stress $\sigma_{\theta}^{a}$, radial stress $\sigma_{r}^{a}$ and equivalent von Mises stresses $\sigma_{\text {rrd }}^{a}$ are plotted along the thickness $h$ of the bimetallic perforated plate in sections $\mathrm{T}_{1}$ and $\mathrm{T}_{2}$, i.e. on the radius $r=\mathrm{R}_{5}=60 \mathrm{~mm}$ and $r=130 \mathrm{~mm}$ (Fig 2), loaded from the side of the titanium layer with a concentrated force applied perpendicularly to the center of the plate $P$ $=10 \mathrm{kN}$.

Bimetallic perforated plate fixed supported on the perimeter and loaded with a concentrated force P acting perpendicular to the surface In the second case, the analysis the state of stress in a bimetallic perforated plate loaded with a concentrated force applied perpendicularly to the surface with the value $P=10 \mathrm{kN}$ was presented below. The geometry of the plate is presented in Fig. 2. The concentrated force $P$ was applied centrally to the pressure stamp with a diameter of $b_{1}=14 \mathrm{~mm}$. A fixed of the plate on the outer perimeter was assumed. The method of support and loading the plate is shown in Fig. 6.

The boundary conditions are assumed to take the following form (Fig. 6):

a) for the radius $r-1 / 2 b=6 \mathrm{~mm}-$ plate deflection angle $\varphi=0$;

b) for the radius $r=1 / 2 D=150 \mathrm{~mm}$ - plate deflection angle $\varphi=0$. 

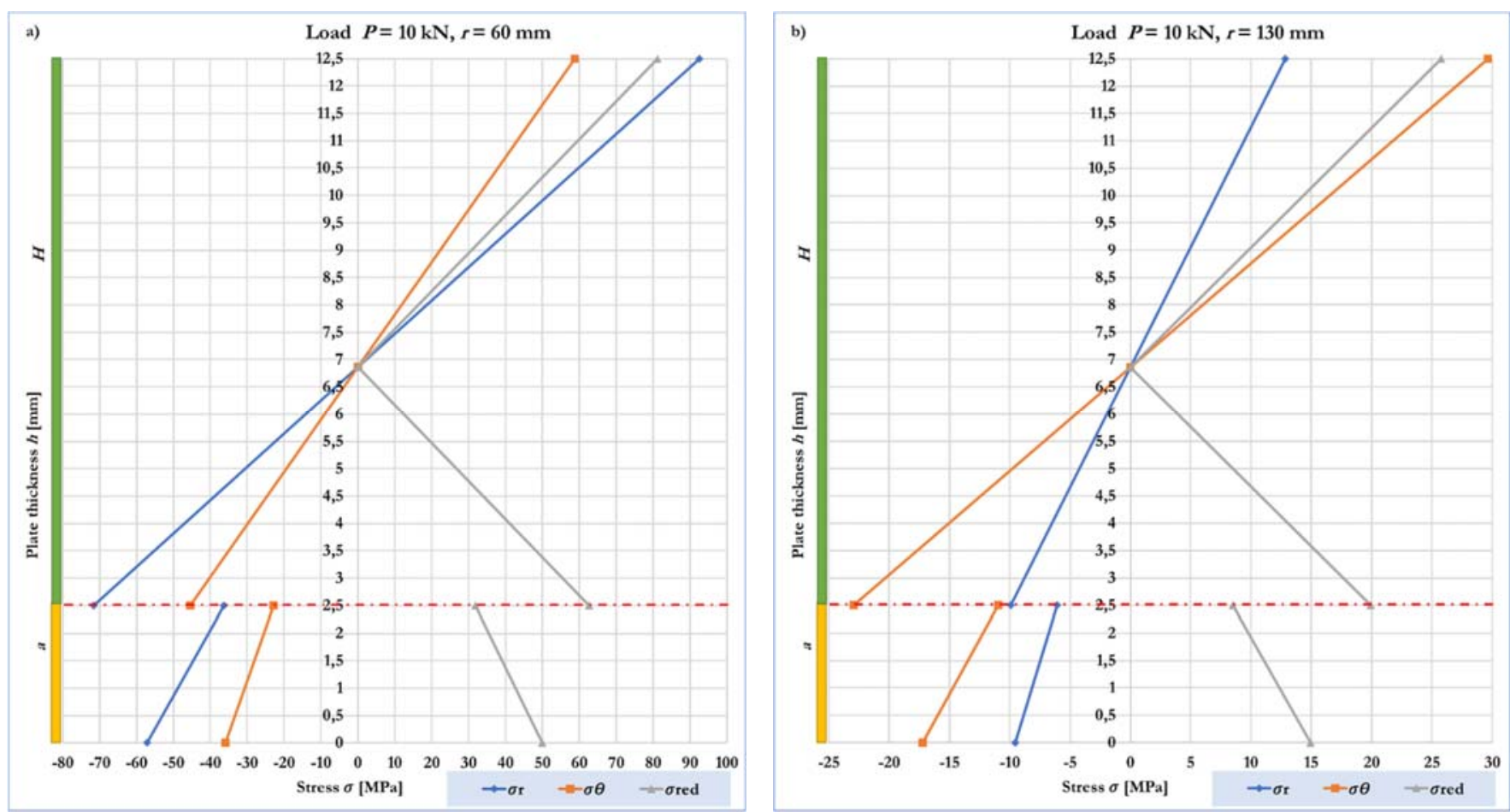

Figure 5. Stress distribution, respectively: $\sigma_{\theta}^{a}, \sigma_{r}^{a}$, and $\sigma_{r e d}^{a}$ in the cross-section of a bimetallic perforated plate freely supported and loaded with a concentrated force with the value $P=10 \mathrm{kN}$ : a) in the section $\mathrm{T}_{1}$ on the radius $r=\mathrm{R}_{5}=60 \mathrm{~mm}$; b) in the section $\mathrm{T}_{2}$ on radius $r=130 \mathrm{~mm}$ (Fig. 2).

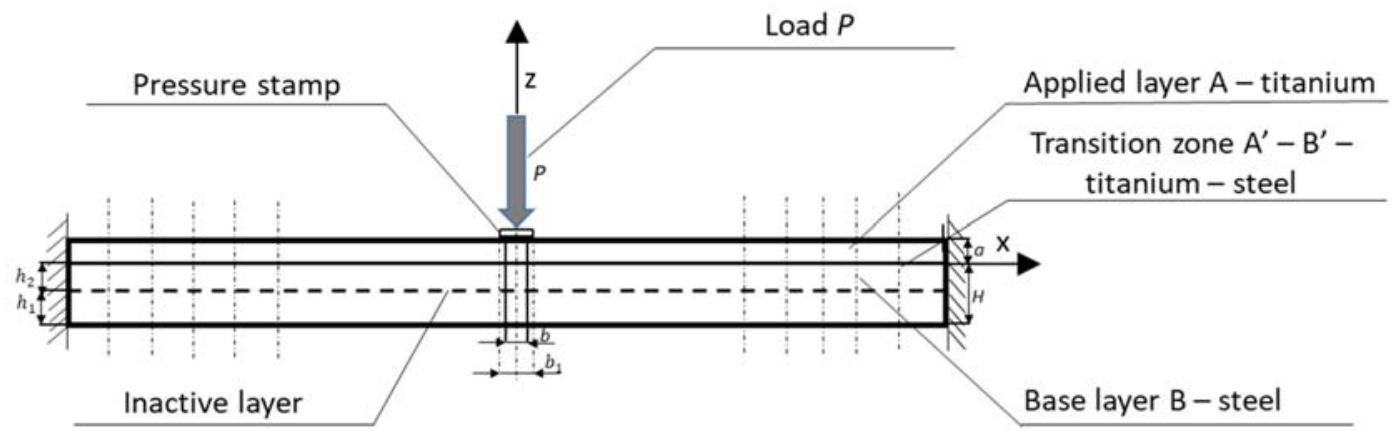

Figure 6. Bimetallic perforated plate fixed on the perimeter and loaded with a concentrated force $P$ acting perpendicular to the surface

In this case, the coefficients $k_{1}, k_{2}, k_{3}$ inside the function of the lateral force intensity $t(r)(6)$ are equal to, respectively:

$$
k_{1}=0 ; k_{2}=\frac{P}{2 \pi} ; k_{3}=0
$$

The roots of the Eqn. (8) $\lambda_{1}$ and $\lambda_{2}$ are:

$$
\lambda_{1}=1.127[-] ; \lambda_{2}=-1.065[-]
$$

Integration constants $D_{1}$ and $D_{2}$ in the Eqn. (7) are equal to:

$$
D_{1}=-1.322 * 10^{-7} k_{2}[\mathrm{~mm}] ; D_{2}=-3.219 * 10^{-5} k_{2}[\mathrm{~mm}]
$$


Cross-section weakening coefficients (4) $C_{\theta}$ and $C_{r}$ in the analyzed plate are respectively:

$$
C_{\theta}=0.590[-] ; C_{r}=0.496[-]
$$

Data as in the above case were adopted for the calculations. On the other hand, the mechanical properties of the steel plate and the titanium plate were taken from Tab. 1.

On the basis of the Eqns. (10) - (15), values of radial stresses $\sigma_{r}^{a}$ and circumferential $\sigma_{\theta}^{a}$ and equivalent von Mises stresses $\sigma_{\text {red }}^{a}$ were determined for the adopted geometry of the bimetallic perforated plate given in Fig. 6. For example, in Fig. 7 the values of the circumferential stress $\sigma_{\theta}^{a}$, radial stress $\sigma_{r}^{a}$ and equivalent von Mises stresses $\sigma_{\text {red }}^{a}$ are plotted along the thickness $h$ of the bimetallic perforated plate in sections $\mathrm{T}_{1}$ and $\mathrm{T}_{2}$, i.e. on the radius $r=\mathrm{R}_{5}=60 \mathrm{~mm}$ and $r=130 \mathrm{~mm}$ (Fig 2), loaded from the side of the titanium layer with a concentrated force applied perpendicularly to the center of the plate $P$ $=10 \mathrm{kN}$.
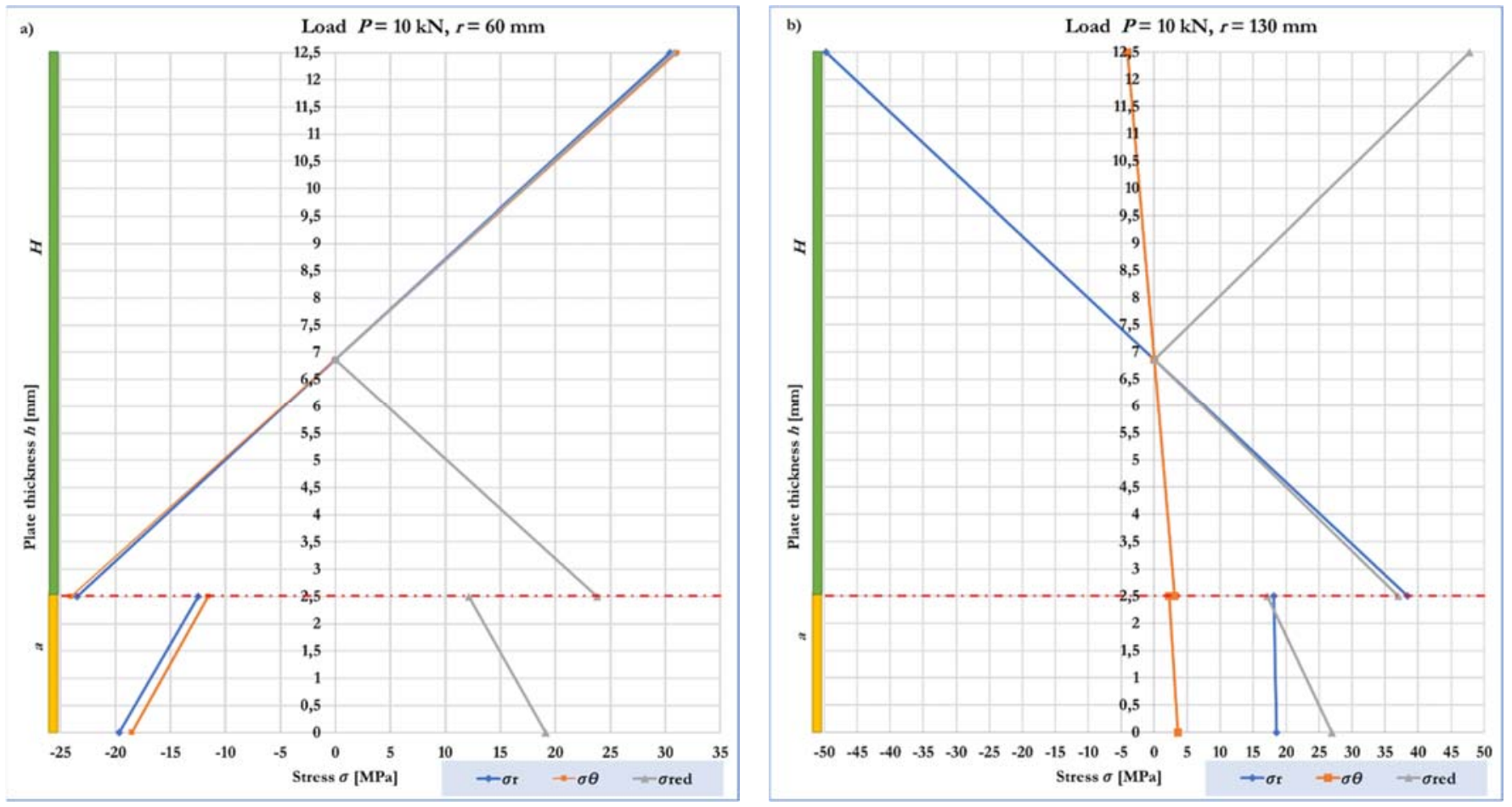

Figure 7. Stress distribution, respectively: $\sigma_{\theta}^{a}, \sigma_{r}^{a}$, and $\sigma_{\text {red }}^{a}$ in the cross-section of a bimetallic perforated plate fixed and loaded with a concentrated force with the value $P=10 \mathrm{kN}$ : a) in the section $\mathrm{T}_{1}$ on the radius $r=R_{5}=60 \mathrm{~mm}$; $\mathrm{b}$ in the section $\mathrm{T}_{2}$ on radius $r=$ $130 \mathrm{~mm}$ (Fig. 2).

\section{NUMERICAL METHOD}

he subject of numerical calculations was the stress distribution in a bimetallic circular perforated plate, in the first case freely supported (Fig. 4) and in the second case fixed (Fig. 6) and loaded with a concentrated force applied perpendicular to the center of the plate. The free support of the plate was realized by designing a ring support on which a bimetallic perforated plate was placed. Minimal friction contact is applied between the plate and the support. On the other hand, the plate was fixed by removing all degrees of freedom from the finite elements located on the outer contour of the perforated plate. 
The three-dimensional 3D computational model of the bimetallic circular axially-symmetrical perforated plate was created and discretized by the possibility of modeling and creating a finite element mesh in ANSYS [17]. The finite elements used for discretization were SOLID186 finite elements. The calculation model contained the total number of 3379707 finite elements, while the total number of nodes was 7027927 . The entire plate had 25 layers of finite elements (20 layers of base plate and 5 layers of applied layer) (Fig. 8).

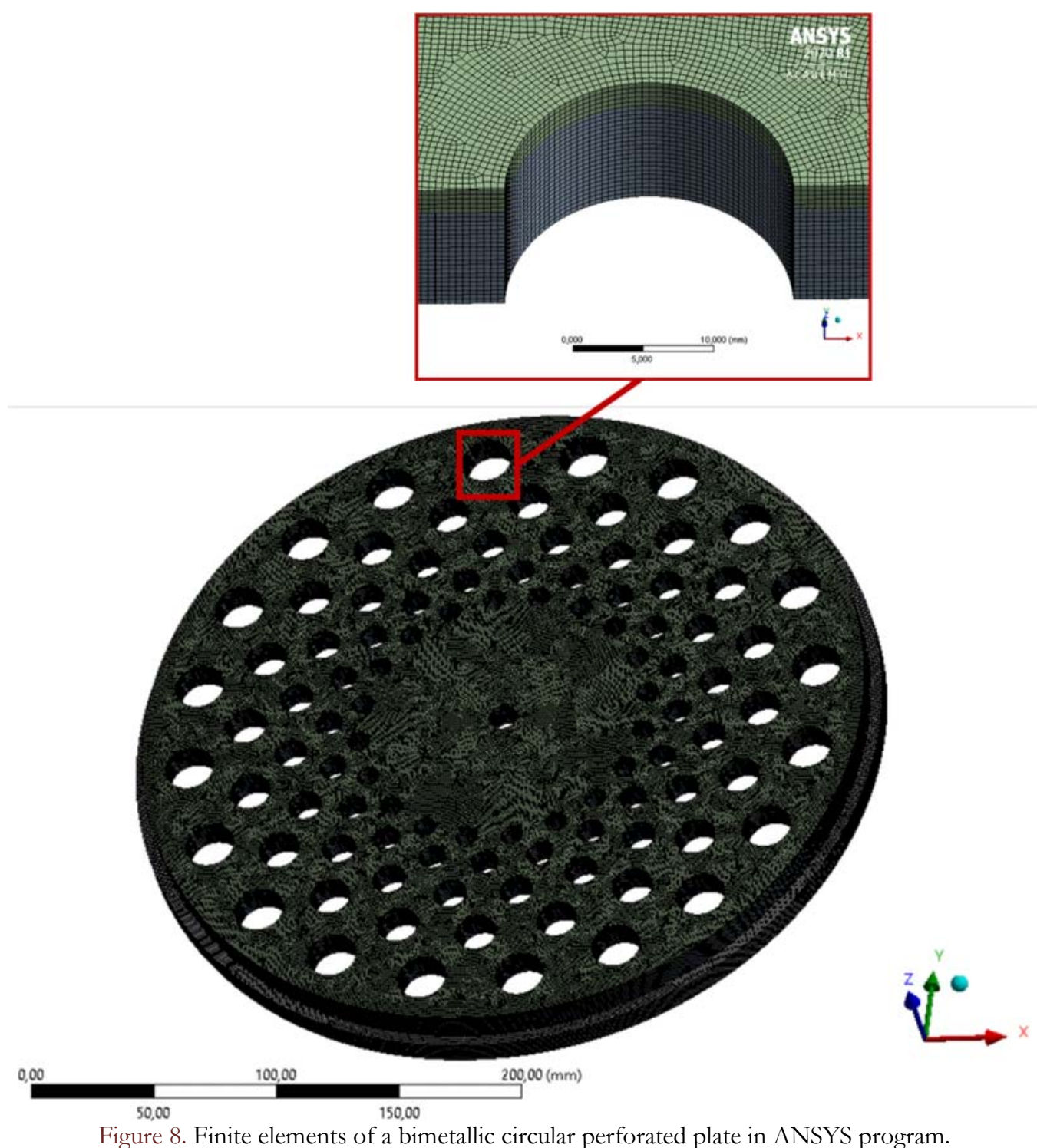

The base layer of the B - steel plate is combined with the applied layer of the A - titanium plate by using the "connections" function, providing the option to bond two or more elements [17]. It was assumed that the combination of the titanium layer and the steel layer of the plates is excellent. Modeling the connection of these two layers, contact was used in the form of inseparable bonding - as both layers were bonded permanently.

Bimetallic perforated plate freely supported on the perimeter and loaded with a concentrated force P acting perpendicular to the surface For example, the distribution of equivalent von Mises stress in the cross section of the plate is presented in Fig. 9. The figure illustrates the distribution of equivalent von Mises stress in a bimetallic perforated plate loaded with a force of $P=$ $10 \mathrm{kN}$ in the applied layer A - titanium, in the applied transition zone A'- titanium, in the based transition zone B' - steel and based layer B - steel determined for the radius $r=R_{5}=60 \mathrm{~mm}$. The following numerical calculation results (Fig. 9) demonstrate the places where the equivalent von Mises stress values occur, i.e. point AP' - the place of maximum equivalent 
von Mises stress near the hole in the titanium transition zone, BP' - the value of the maximum equivalent von Mises stress near the hole in the transition zone of structural steel, AP- the place of maximum equivalent von Mises stress near the hole in the titanium layer, BP - the value of the maximum equivalent von Mises stress near the hole in the structural steel layer. The maximum equivalent von Mises stress around the hole and its coordinates in the vicinity of the hole were respectively: $\sigma_{\text {red } \max }=97.997 \mathrm{MPa}$ in A layer, where AP $[\mathrm{x}=6.0 \mathrm{~mm}, \mathrm{y}=68.51 \mathrm{~mm}, \mathrm{z}=0.0 \mathrm{~mm}], \sigma_{\text {red } \max }=168.83 \mathrm{MPa}$ in B layer, where BP $[\mathrm{x}=6.0 \mathrm{~mm}, \mathrm{y}=68.81 \mathrm{~mm}, \mathrm{z}=12.5 \mathrm{~mm}]$, while $\sigma_{\text {red } \max }=66.417 \mathrm{MPa}$ in A' zone, where AP' $[\mathrm{x}=6.0 \mathrm{~mm}, \mathrm{y}=$ $68.51 \mathrm{~mm}, \mathrm{z}=2.49 \mathrm{~mm}$ ] and $\sigma_{\text {red } \max }=130.27 \mathrm{MPa}$ in $\mathrm{B}^{\prime}$ zone, where BP' $[\mathrm{x}=6.0 \mathrm{~mm}, \mathrm{y}=68.51 \mathrm{~mm}, \mathrm{z}=2.51 \mathrm{~mm}$.

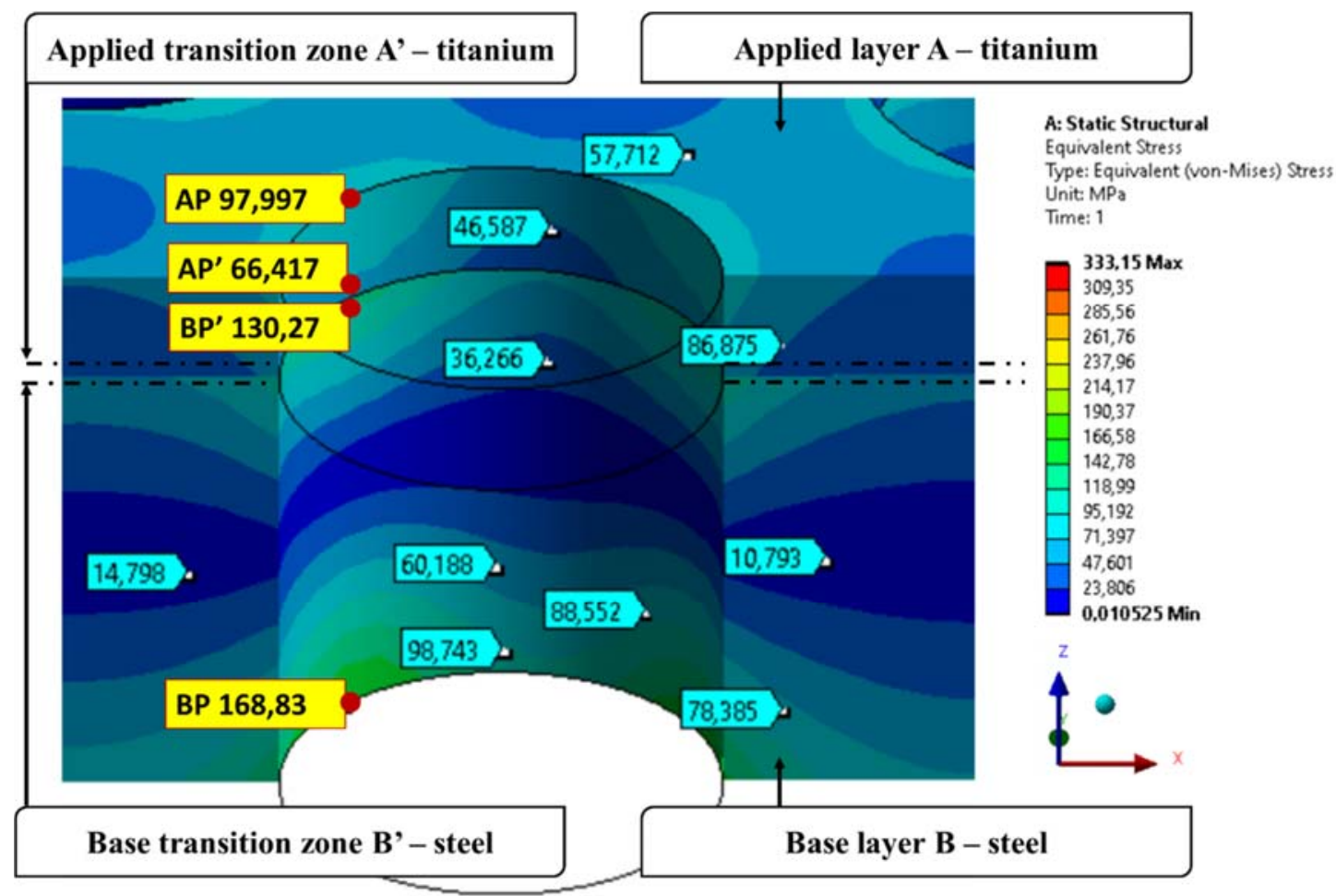

Figure 9. Distribution of equivalent von Mises stress $\sigma_{\text {red }}^{n}$ in the cross section of the plate determined on the radius $r=R_{5}=60$ mm.

Whereas in Fig. 7 the values of the circumferential stress $\sigma_{\theta}^{a}$, radial stress $\sigma_{r}^{a}$ and equivalent von Mises stresses $\sigma_{r e d}^{a}$ are plotted along the thickness $h$ of the bimetallic perforated plate in sections $\mathrm{T}_{1}$ and $\mathrm{T}_{2}$, i.e. on the radius $r=\mathrm{R}_{5}=60 \mathrm{~mm}$ and $r=130 \mathrm{~mm}$ (Fig 2), loaded from the side of the titanium layer with a concentrated force applied perpendicularly to the center of the plate $P=10 \mathrm{kN}$.

Bimetallic perforated plate fixed supported on the perimeter and loaded with a concentrated force P acting perpendicular to the surface For example, the distribution of equivalent von Mises stress in the cross section of the plate is presented in Fig. 11. The figure illustrates the distribution of equivalent von Mises stress in a bimetallic perforated plate loaded with a force of $P=$ $10 \mathrm{kN}$ in the applied layer A - titanium, in the applied transition zone A'- titanium, in the based transition zone B' - steel and based layer $\mathrm{B}$ - steel determined for the radius $r=R_{5}=60 \mathrm{~mm}$. The following numerical calculation results (Fig. 11) demonstrate the places where the equivalent von Mises stress values occur, i.e. point AP' - the place of maximum equivalent von Mises stress near the hole in the titanium transition zone, BP' - the value of the maximum equivalent von Mises stress near the hole in the transition zone of structural steel, AP- the place of maximum equivalent von Mises stress near the hole in the titanium layer, BP - the value of the maximum equivalent von Mises stress near the hole in the structural steel layer. The maximum equivalent von Mises stress around the hole and its coordinates in the vicinity of the hole were respectively: $\sigma_{\text {red } \max }=51.155 \mathrm{MPa}$ in A layer, where AP $[\mathrm{x}=8.88 \mathrm{~mm}, \mathrm{y}=-54.81 \mathrm{~mm}, \mathrm{z}=0.0 \mathrm{~mm}], \sigma_{\text {red } \max }=91.816 \mathrm{MPa}$ in $\mathrm{B}$ layer, where BP $\left[\mathrm{x}=8.88 \mathrm{~mm}, \mathrm{y}=-54.81 \mathrm{~mm}, \mathrm{z}=12.5 \mathrm{~mm}\right.$, while $\sigma_{\text {red } \max }=32.258 \mathrm{MPa}$ in A' zone, where AP' $[\mathrm{x}=8.88 \mathrm{~mm}$, $\mathrm{y}=-54,81 \mathrm{~mm}, \mathrm{z}=2.49 \mathrm{~mm}$ ] and $\sigma_{\text {red } \max }=71.527 \mathrm{MPa}$ in $\mathrm{B}^{\prime}$ zone, where BP' $[\mathrm{x}=8.88 \mathrm{~mm}, \mathrm{y}=-54.81 \mathrm{~mm}, \mathrm{z}=2.51$ $\mathrm{mm}]$. 

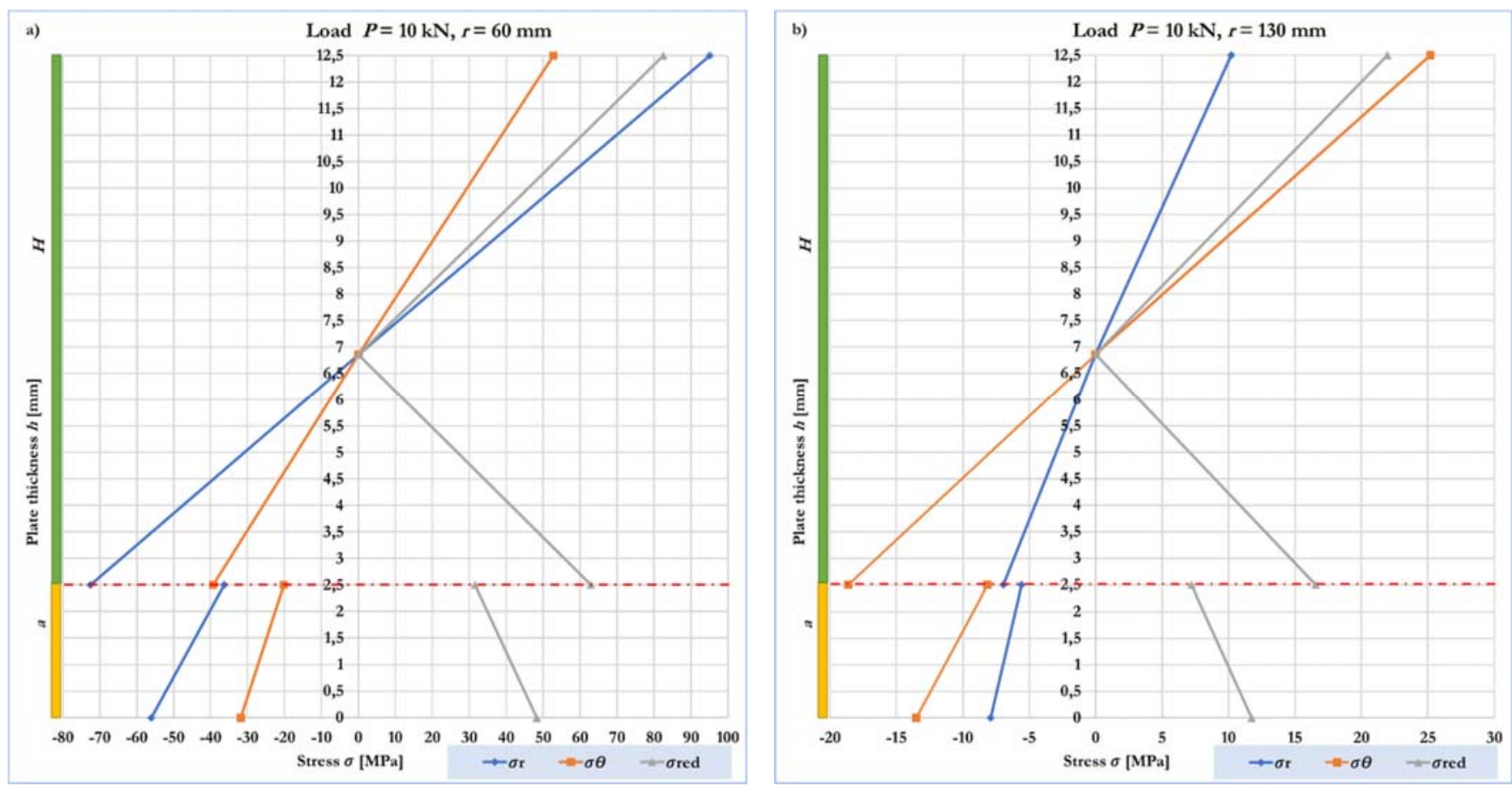

Figure 10. Stress distribution, respectively: $\sigma_{\theta}^{n}, \sigma_{r}^{n}$, and $\sigma_{r e d}^{n}$ in the cross-section of a bimetallic perforated plate freely supported and loaded with a concentrated force with the value $P=10 \mathrm{kN}$ : a) in the section $\mathrm{T}_{1}$ on the radius $r=R_{5}=60 \mathrm{~mm}$; $\mathrm{b}$ ) in the section $\mathrm{T}_{2}$ on radius $r=130 \mathrm{~mm}$ (Fig. 2).

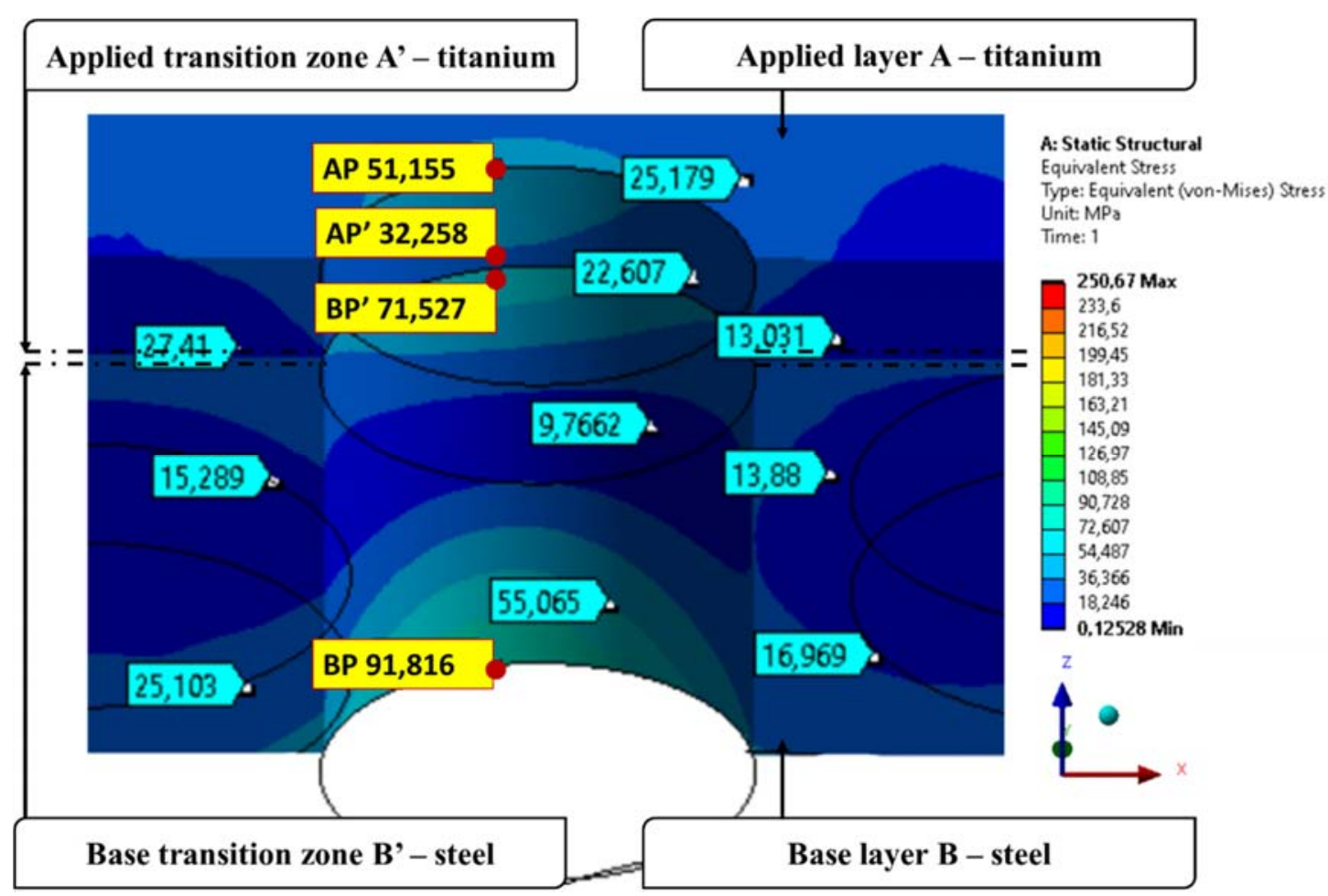

Figure 11. Distribution of equivalent von Mises stress $\sigma_{r e d}^{n}$ in the cross section of the plate determined on the radius $r=R_{5}=60 \mathrm{~mm}$. 
Whereas in Fig. 12 the values of the circumferential stress $\sigma_{\theta}^{a}$, radial stress $\sigma_{r}^{a}$ and equivalent von Mises stresses $\sigma_{r e d}^{a}$ are plotted along the thickness $h$ of the bimetallic perforated plate in sections $\mathrm{T}_{1}$ and $\mathrm{T}_{2}$, i.e. on the radius $r=\mathrm{R}_{5}=60 \mathrm{~mm}$ and $r=130 \mathrm{~mm}$ (Fig 2), loaded from the side of the titanium layer with a concentrated force applied perpendicularly to the center of the plate $P=10 \mathrm{kN}$.
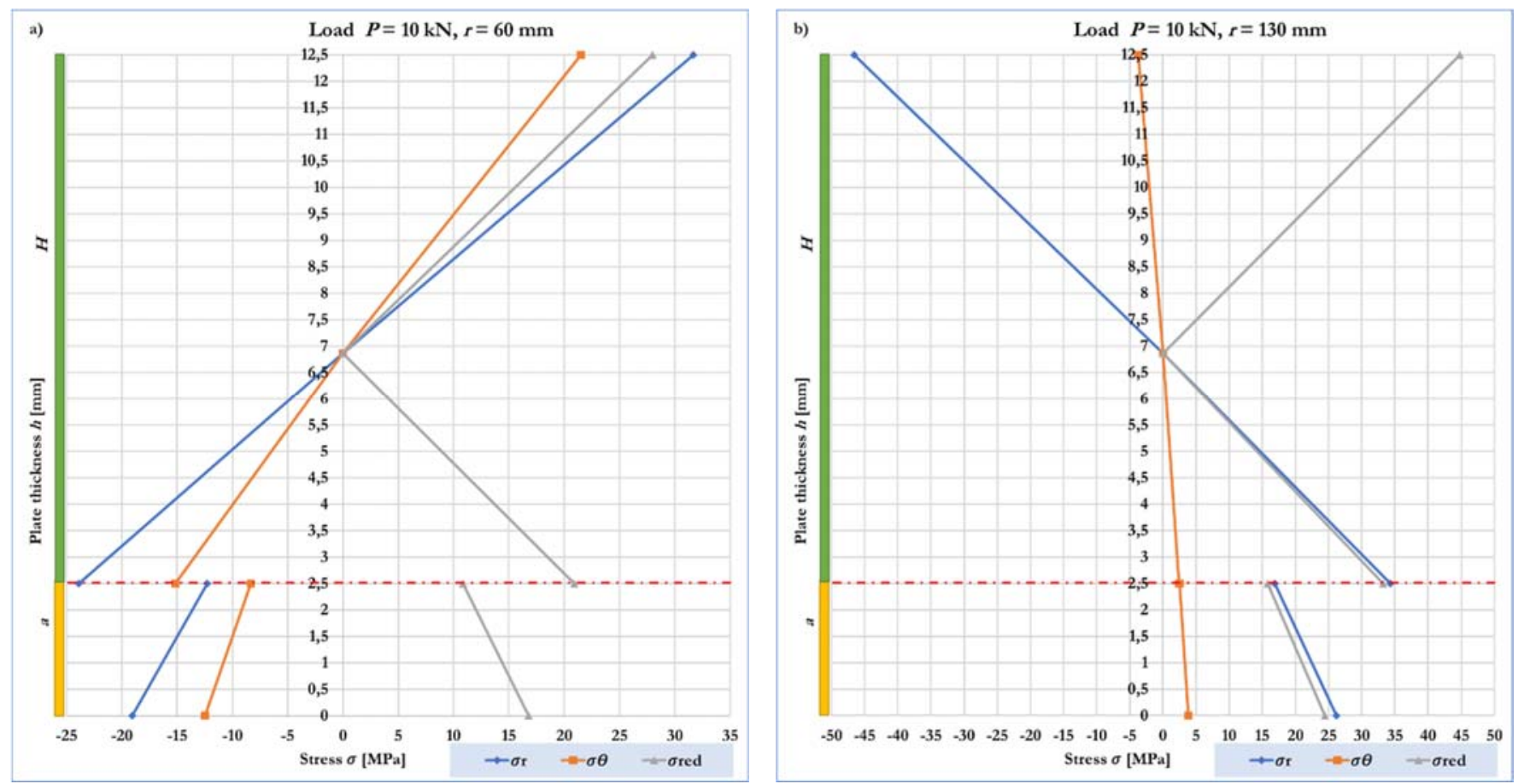

Figure 12. Stress distribution, respectively: $\sigma_{\theta}^{n}, \sigma_{r}^{n}$, and $\sigma_{r e d}^{n}$ in the cross-section of a bimetallic perforated plate fixed and loaded with a concentrated force with the value $P=10 \mathrm{kN}$ : a) in the section $\mathrm{T}_{1}$ on the radius $r=R_{5}=60 \mathrm{~mm}$; ) in the section $\mathrm{T}_{2}$ on radius $r=$ $130 \mathrm{~mm}$ (Fig. 2).

\section{RESULTS OF THE RESEARCH}

7 he problem of the stress analysis on the plate thickness, taken up in the paper, enables the appropriate selection of the base layer of the steel plate as well as the layer of the applied plate - titanium. The base layer is the layer that carries the load in the plate, in this case it is the steel layer of the plate. However, in this case, the titanium layer of the plate is used due to the improvement of the plate properties, e.g. corrosion resistance, thermal permeability, etc. The thickness of the applied layers, depending on the type of use of the plated plate, may be from $1.5-15 \%$ of the thickness of the base plate. Taking into account the thickness of the layer of the applied plate during design also affects the strength of the bimetallic perforated plate.

For example, Fig. 13 shows the values equivalent von Mises stresses obtained numerically by the finite element method $\sigma_{\text {red }}^{n}$ and analytically $\sigma_{r e d}^{a}$ in a bimetallic circular perforated plate freely supported on the edge and loaded centrally with a concentrated force $P=10 \mathrm{kN}$ perpendicular to the plate surface and the percentage difference between the results obtained for these cases $\delta \sigma_{r e d}$. For example, Fig. 14 presents the values of equivalent von Mises stresses obtained numerically using the finite element method $\sigma_{\text {red }}^{n}$ and analytically $\sigma_{\text {red }}^{a}$ in a bimetallic circular perforated plate fixed at the edge and loaded centrally with a concentrated force $P=10 \mathrm{kN}$ acting perpendicular to the plate surface and the percentage difference between the results obtained for these cases $\delta \sigma_{\text {red }}$.

Apart from numerical calculations the state of stress using the finite element method, an attempt was made to develop analytical equations allowing to determine the stress values in a bimetallic perforated plate subjected to a normal load in the form of a concentrated force. The results the state of stress calculations obtained according to the analytical method were 
compared with the results obtained by the finite element method according to the ANSYS program. The results of these comparisons are presented in Fig. 13 - in the case of freely supported plate and in Fig. 14 - in the case of fixed edges, respectively. Fig. 13 shows that the maximum difference in the stress values is equivalent von Mises stress $\delta \sigma_{\text {red }}^{a}=-7.49 \%$. On the other hand, Fig. 14 shows that the maximum difference in the stress values is equivalent von Mises stress $\delta \sigma_{\text {red }}^{a}=12.34 \%$. The calculations carried out in the work with the analytical and numerical method using the ANSYS program show that the maximum difference in the results obtained with these methods in the case of equivalent von Mises stress is $\delta \sigma_{r e d}^{a}=12.34 \%$. (around $13 \%$ ), i.e.:

$$
\delta \sigma_{\text {red }}^{a}=\frac{\sigma_{\text {red }}^{a}-\sigma_{r e d}^{n} * 100 \%}{\sigma_{\text {red }}^{a}}
$$

where: $\sigma_{r e d}^{n}, \sigma_{r e d}^{n}$-equivalent vo Mises stress determined by analytical and numerical methods, respectively.

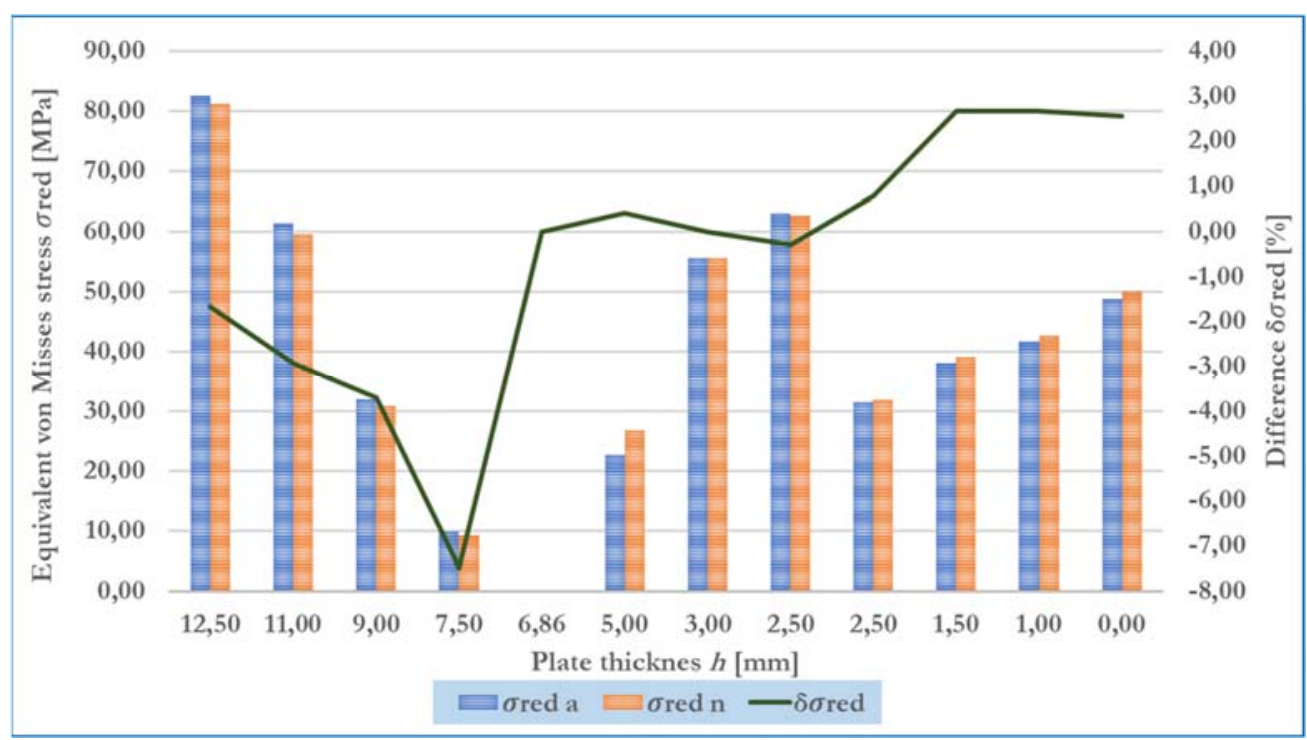

Figure 13: Comparison of equivalent von Mises stress $\sigma_{\text {red }}$ determined analytically and numerically in the cross-section of the bimetallic perforated plate freely supported and loaded with a concentrated force $P=10 \mathrm{kN}$ determined on the radius $r=R_{5}=60 \mathrm{~mm}$.

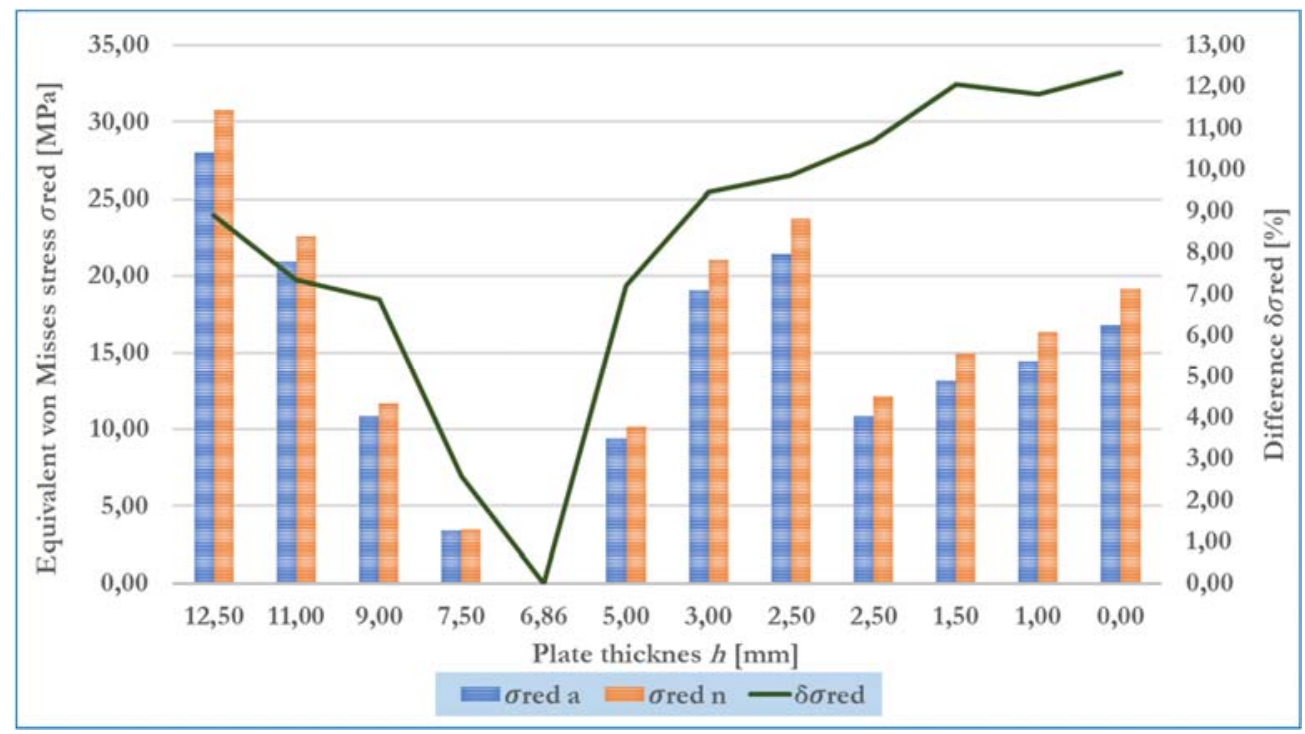

Figure 14: Comparison of equivalent von Mises stress $\sigma_{\text {red }}$ determined analytically and numerically in the cross-section of the bimetallic perforated plate fixed and loaded with a concentrated force $P=10 \mathrm{kN}$ determined on the radius $r=R_{5}=60 \mathrm{~mm}$. 
A significant difference in the results obtained with the analytical method and the finite element method results from the fact that the bimetallic plate has a perforation, which causes a significant heterogeneity of the material, which was fully taken into account in the analytical solution. Therefore, it is believed that the error of about $13 \%$ is the discrepancy between the results obtained by the analytical method and the results obtained with the ANSYS program.

The paper shows that the ANSYS program allows to determine the state of stress in a sufficiently accurate state in a bimetallic perforated plate at any point, i.e. on the bridge between the holes, around the holes, along the thickness of the titanium layer and the steel layer. It also enables the determination of stress concentration zones, and thus the location of dangerous places in the designed plate. Knowing the coordinates of stress concentration points, it is possible to predict the zones of crack initiation and propagation in bimetallic perforated plates.

Despite significant differences in the stress values determined by the analytical method, it is believed that the analytical solution of the state of stress in a bimetallic perforated plate may be helpful for engineers to estimate the effort of the designed multilayer structures of the perforated plate type. It should be mentioned that the use of analytical solutions when designing bimetallic perforated plates allows to obtain the stress values in the structure relatively quickly.

The paper shows that the method of supporting a bimetallic perforated plate has a significant impact on its state of stress. Tabs. 2 and 3 show that for the same load, the stresses in the plate freely supported along the perimeter are higher in relation to the plate fixed at the edge.

The graphs in Figs. 5, 7, 10 and 12 show that both the analytical method and the ANSYS program, engineers can present the curves of the circumferential stress $\sigma_{\theta}$, radial stress $\sigma_{r}$, equivalent von Mises stress $\sigma_{\text {red }}$ distributions along the plate thickness, both in the applied layer - titanium, the base layer - steel and in the transition zone between the overlay and the edge layer. The existence of a significant difference in the stress values in the transition zone between the applied layer A' titanium and the base layer B' - steel.

Figs. 9 and 11 show as an example the location of points along the plate thickness, where we plate with the maximum values of equivalent von Mises stresses obtained by the ANSYS program. The analytical method does not provide such possibilities.

\section{CONCLUSIONS}

he following conclusions can be drawn from the above analysis:

1) The attempt to use the analytical method to determine the state of stress in a bimetallic perforated plate

L resulted in the discrepancy of the calculation results in the equivalent von Mises stress values in comparison with the finite element method, up to approximately $13 \%$;

2) It is proposed that the analytical method be recommended to design engineers as a tool for the estimation of the state of stress of multilayer perforated plates;

3) It was shown that in the transition zone of the plate between the applied layer - titanium and the base layer - steel, there is a step change in stress values.

\section{REFERENCES}

[1] Cheng Wu, X.J. (1999). A higher order theory for plane stress conditions of laminates consisting of isotropic layers, Journal of Applied Mechanics, 66, pp. 95-100.

[2] Jafari, M., Mounssavian, H. and Chaleshtari, M.H. (2018). Optimum Design of Perforated Orthotropic and Laminated Composite Plates under in-plane Loading by Genetic Algorithm, Structural and Multidisciplinary Optimization, 57, pp. 341-357, DOI: 10.1007/s00158-017-1758-5.

[3] Shaikh, E.N., Panchal, K.C. and Patel, D.B. (2015). Stress analysis of an infinite plate with different shaped cutouts in composite plate, International Journal of Science Technology and Management, 4 (1), pp. 307-317.

[4] Kosturek, R., Wachowski, M., Śnieżek, L. and Gloc, M. (2018). The Influence of the Post Weld Heat Treatment on the Microstructure of Inconel 625/Carbon Steel Bimetal Joint Obtained by Explosive Welding, www.preprints.org., pp. 115.

[5] Konieczny, M., Achtelik, H. and Gasiak, G. (2020). Stress distribution in plated perforated plate loaded centrally with concentrated force, Zmęczenie materiału w eksploatacji maszyn roboczych, PO, 2, pp. 47-62 (in Polish).

[6] Walczak, W. (1989). Metal explosion welding. WTN, Warsaw (in Polish). 
[7] Konieczny, M., Achtelik, H. and Gasiak, G. (2020). Finite Element Analysis (FEA) and experimental stress analysis in circular perforated plates loaded with concentrated force, Frattura ed Integrità Strutturale, 51, pp. 164-173, DOI: 10.3221/IGF-ESIS.51.13.

[8] Konieczny, M., Achtelik, H. and Gasiak, G. (2019). Research of maximum stresses zones in circular perforated plates made of S235JR steel loaded with concentrated force, Materials Engineering, 2 (228), pp. 39-46, DOI: $10.15199 / 28.2019 .2 .4$.

[9] Konieczny, M., Achtelik, H. and Gasiak, G. (2020). Analysis of Reduced Stress Distribution in Circular Perforated Plates, Fundamentals of Machine Design: Selected problems, Military University of Technology, pp. 133-145.

[10] Kurek, A., Niesłony, A. and Szulc, Z. (2013). Design of process equipment made from explosively cladded materials, including the imposed material thickness in calculations, Przegląd Mechaniczny, 12, pp. 22-27.

[11] Karolczuk, A., Kowalski, M., Bański, R. and Żok, F. (2013). Fatigue phenomena in explosively welded steel - titanium clad components subjected to push-pull loading, International Journal of Fatigue, 48, pp. 101-108, DOI: 10.1016/j.ijfatigue.2012.10.007 .

[12] Karolczuk, A. and Kowalski, M. (2013). Residual stress determination based on the hole drilling method in explosively welded bimetallic composite, Third International Conference on Material Modelling, Warsaw, p. 140.

[13] Konieczny, M., Achtelik, H. and Gasiak, G. (2021). Location of stress concentration zones in a two-layer axially symmetrical perforated plate with force applied normally to its surface, Engineering Structures, 226 , pp. 1-14, DOI: $10.1016 /$ j.engstruct.2020.111355.

[14] Data from Explomet Company research (Z.T.W. EXPLOMET, Gałka, Szulc, Sp. j. ul. Oświęcimska 100H, 45-641 Opole, Poland).

[15] Timoshenko, S. and Woinowsky - Krieger, S. (1959). Theory of plates and shells, $2^{\text {nd }}$ ed. New York, McGraw - Hill Book Company, pp. 62-85.

[16] Achtelik, H., Gasiak, G. and Grzelak, J. (2008). Strength tests of axially symmetric perforated plates for chemical reactors: Part 1 - The simulation of stress state, International Journal of Pressure Vessels and Piping, 85, pp. 248-256, DOI: 10.1016/j.ijpvp.2007.08.009.

[17] User’s Guide ANSYS 2020 R1, Ansys, Inc., USA.

\section{NOMENCLATURE}

$H, a$ - thickness of steel and titanium plate, respectively;

$b$ - thickness of plate;

$D$ - diameter of the circular axially-symmetrical plated perforated plate;

$b$ - diameter of the hole in the central part of the plate;

$b_{1}$ - pressure stamp diameter;

$C_{n} C_{\theta}$ - coefficients of weakening of the plate cross-section due to the existence of discontinuities in the form of holes in the radial and circumferential directions, respectively;

$B^{*}, B^{* *}$ - plate stiffness coefficients;

$\varphi=\varphi(r)$ - tilt angle of the tangent to the curved central surface of the plate;

$k_{1}, k_{2}, k_{3}-$ coefficients of the lateral force function;

$m_{\theta 1}, m_{\theta 2}-$ circumferential torque intensity in the steel and titanium parts, respectively;

$m_{r 1}, m_{r 2}-$ radial moment intensity in the steel and titanium parts, respectively;

$\lambda_{1}, \lambda_{2}$ - roots of the characteristic equation for the differential equation of the perforated plate balance;

$D_{1}, D_{2}, D_{3}$ - integration constants;

$r, \theta$ - radial and peripheral coordinates of the plate;

$\sigma_{\theta_{1}}, \sigma_{\theta_{2}}$ - circumferential stress in the steel and titanium parts, respectively;

$\sigma_{r_{1}}, \sigma_{r_{2}}-$ radial stress in the steel and titanium parts, respectively;

$E_{1}, E_{2}, v_{1}, v_{2}$ - Young's modules and Poisson's coefficients for steel and titanium parts; $h_{1}, h_{2}-$ values determining the position of the inactive layer in the cross-section of the plated plate;

$B_{1}, B_{2}$ - bending stiffness of the steel and titanium layer, respectively;

$t(r)$ - intensity of the transverse force acting in the cross-sections of the plated plate;

$w=w(r)-$ deflection of the perforated plate; 
$\sigma_{\text {red }_{1}}, \sigma_{\text {red }_{2}}$ - equivalent von Mises stress in steel and titanium parts, respectively;

$R_{n}$ - radius of the circles on which the holes on the plate are arranged;

$d_{n}$ - diameter of the holes;

$P$ - load in the form of concentrated force;

$r$ - radius of the circles on which the measuring points are located;

$T_{1}, T_{2}-$ sections;

B - base (steel) layer of the plate;

B' - basic transition zone (from the steel side) of the plate;

$A^{\prime}$ - transition zone applied (from the titanium side) to the plate;

A - applied (titanium) layer of the plate. 